\title{
A MÁQUINA DE TORTURA: UMA SÍNTESE DOS EFEITOS DO VESTIBULAR NA EDUCAÇÃO E NA SOCIEDADE.
}

\author{
Roberto Fernando de Amorim Júnior ${ }^{1}$ e Dante Henrique Moura ${ }^{2}$ \\ ${ }^{1}$ Graduando do Curso de Licenciatura Plena em Geografia do CEFET-RN. \\ robertoamorim175@yahoo.com \\ ${ }^{2}$ Professor do CEFET-RN. Engenheiro Eletricista, Doutor em Educação. \\ dante@cefetrn.br
}

Recebido em abril de 2005 e Aceito em setembro de 2005

\section{RESUMO}

O presente artigo trata de discutir uma das formas de acesso ao ensino superior mais utilizado no Brasil: o vestibular. A partir de várias leituras e de experiências anteriormente vivenciadas, concluímos que o vestibular vem causando danos à nossa educação. Tais danos revelam-se na prática bancária de ensino dentro das salas de aula, no aumento das diferenças sociais, na falta de democracia no acesso às universidades, no desprestígio da função do educador, no aumento da fragmentação do conhecimento e na desconstrução de uma educação emancipadora. Diante disso, propomos neste artigo algumas políticas para superar essas dificuldades, enfatizando uma educação que proporcione condições igualitárias de acesso à educação superior para todos.

Palavras-chave: ensino, vestibular, educação.

\section{LA MÁQUINA DE TORTURA: UN BREVE ESTUDIO SOBRE LOS EFECTOS DE LA SELECTIVIDAD EN LA EDUCACIÓN Y EN LA SOCIEDAD.}

\section{RESUMEN}

El presente artículo analiza una de las formas de acceso a la educación superior más utilizado en Brasil: la selectividad. A partir de diversas lecturas y de experiencias anteriores, concluimos que la selectividad esta causando daños a nuestra educación. Esos daños se manifestan en la práctica bancaria de la enseñanza en el aula, en el aumento de las diferencias sociales, en la falta de democracia en el acceso a universidad, en el desprestigio de la función del educador, en el aumento de la fragmentación del conocimiento y en la desconstrución de una educación libertadora. Ante eso, proponemos en este artículo algunas políticas para superar esas dificultades, resaltando una educación que proporcione condiciones de igualdad de acceso la educación superior para todos.

Palabras-clave: enseñanza, selectividad, educación. 


\section{A MÁQUINA DE TORTURA: UMA SÍNTESE DOS EFEITOS DO VESTIBULAR NA EDUCAÇÃO E NA SOCIEDADE.}

\section{INTRODUÇÃO}

O vestibular é a forma de acesso à educação superior mais utilizada no Brasil. Basta uma breve reflexão sobre esse tema para se constatar que se trata de um sistema antidemocrático, pois não proporciona igualdade de acesso às diferentes classes sociais existentes. O que observamos é que nesse funil, semestral ou anualmente, competem por vagas na educação de nível superior alunos oriundos de escola pública com alunos de escola privada, como se as condições fossem iguais para ambos.

Enquanto que os cursos mais elitizados das instituições públicas federais e estaduais de nível superior são ocupados por alunos provenientes de escolas privadas, os cursos menos valorizados socialmente são aproveitados pelos estudantes egressos do sistema público de educação. Através dessa realidade constatamos uma segregação acadêmica dentro das instituições de nível de educação superior. Esse é apenas um dos vários problemas que o vestibular vem proporcionando a nossa sociedade, mas não se restringe a apenas ele.

Sendo assim, no presente texto, inicialmente, enfocamos alguns aspectos da reforma do ensino superior. Realizamos algumas reflexões sobre pontos importantes e que devem ser seriamente discutidos em conjunto com os setores que compõe a sociedade, pois a omissão deles poderá vender uma imagem falaciosa da reforma.

Em seguida, propomos algumas alternativas para efetivar não somente uma inclusão, como também, uma integração das camadas mais pobres na sociedade. Dentre essas alternativas, ressaltamos a inclusão educacional.

Além da necessidade de melhores salários, maior participação da sociedade nos conteúdos programáticos, melhorias na formação do educador, avaliação do profissional da educação, maior infra-estrutura nas salas de aula e implementação de uma escola única, laica e universal, acreditamos que a forma de acesso à educação pública de nível superior deva ser outro elemento bastante discutido com a sociedade e articulado com os demais.

Para isso, este texto traz um breve estudo sobre os efeitos que o vestibular vem trazendo à educação, com reflexos em toda a sociedade.

Temos a intenção de não finalizar essa discussão por aqui, mas provocar outros estudos que contribuam para viabilizar novas formas de acesso ou, até mesmo, extinguilas, sem, contudo, afetar negativamente o sistema de educação no Brasil.

\section{UM BREVE PANORAMA DOS ASPECTOS POLÍTICOS, SOCIAIS E ECONÔMICOS DA EDUCAÇÃO SUPERIOR BRASILEIRA NA ATUALIDADE}

Para iniciar, necessitamos primeiramente nos situar na atual conjuntura política, social e econômica da educação brasileira, pois nos últimos anos as instituições de ensino superior têm sido alvo de constantes debates em torno da construção de políticas públicas 
para financiá-las e do número de vagas disponíveis para o ingresso de estudantes provenientes do ensino médio das escolas públicas. Trata-se de uma discussão que objetiva encontrar caminhos para integrar a população de baixa renda à sociedade, além de estimular a consolidação da pesquisa e da extensão no ensino superior, dentre outros aspectos.

Diante disso, não temos dúvidas de que as vagas atualmente disponíveis nas instituições públicas de educação superior são insuficientes. Por outro lado, desde a adoção das idéias neoliberalizantes no Brasil, notamos uma enorme proliferação das instituições privadas de educação básica e superior. No caso do ensino superior, atualmente $71 \%$ das vagas pertencem às instituições privadas, enquanto que $29 \%$ pertencem às públicas (Tabela 1). Assim, mesmo abocanhando grande parte das vagas, na rede de ensino superior privada ainda há vagas ociosas, enquanto na pública o número de vagas não é compatível com a demanda. A partir desses dados, para resolver o problema do acesso dos grupos sociais desfavorecidos ao ensino superior e sua integração à sociedade, o governo vem propondo uma alternativa que acreditamos ser a-crítica, cômoda, economicista e linear.

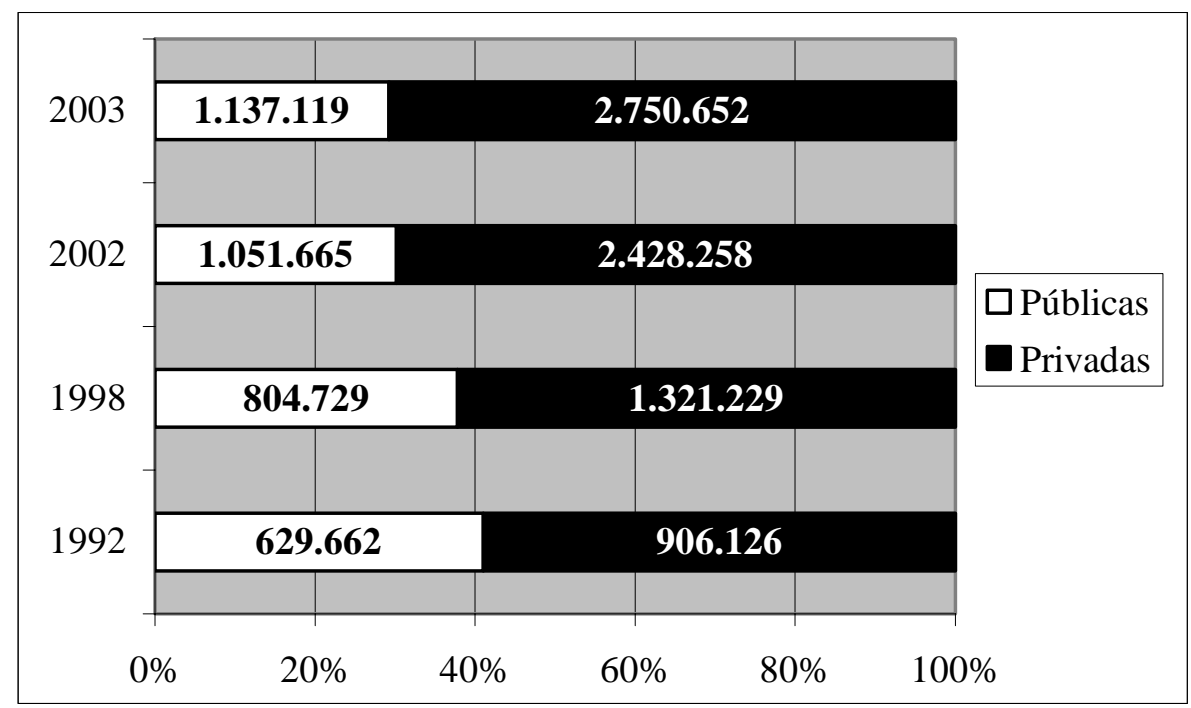

Tabela 1 - Número de Matrículas no Ensino Superior.

Fonte: Ministério da Educação e Cultura. Reforma da Educação Superior.

Disponível em: <www.mec.gov.br/reforma>. Acesso em 31 dez 2004.

Em primeiro lugar, percebe-se claramente que o discurso do governo é a-crítico, pois utiliza-se de uma teoria pedagógica que acredita ser a sociedade harmoniosa, tendendo à integração de seus membros. “A educação emerge aí como um instrumento de correção dessas distorções. Constitui, pois uma força homogeneizadora que tem por função reforçar os laços sociais, promover a coesão e garantir a integração de todos os indivíduos no corpo social” (SAVIANI, 2000, p. 4).

Em segundo lugar ela é cômoda, pois o governo vai buscar nas instituições de educação superior privadas as vagas ociosas que ele afirma serem "públicas”, ao invés de destinar para as instituições públicas de ensino superior mais verbas para ampliação e melhoria dos cursos. 
Em terceiro lugar podemos considerá-la economicista já que privilegia o aumento das vagas em detrimento da qualidade. Muitos cursos, nos últimos anos, submeteram-se ao processo de avaliação realizado pelo governo, mas em nenhum momento foi cogitada a melhoria daqueles cursos que não adquiriram a média necessária para aprovação.

E por último, a solução encontrada para a integração dos grupos sociais desfavorecidos à sociedade é linear, pois não percebe que o problema é mais amplo. Fazendo uma leitura de Kuenzer, Calazans e Garcia (1996), percebemos que a educação não é a única medida capaz de promover o combate à miséria, ao desemprego e à desigualdade social, tampouco se configurou em nosso país num exemplo democrático, garantindo aos educadores liberdade em suas funções de promover o ensino e a integração social dos indivíduos. A educação é gerenciada sob a égide dos opressores, donos do capital e, por isso, é preciso que as reformas educacionais sejam executadas de acordo com as exigências de quem os financia. Segundo Dieterich (1999, p. 87), citado por Moura (2004, disponível em <http://ww.uff.br/trabalhonecessário/> Acesso em 15 ago. 2004),

é certamente demagógico afirmar que a miséria latinoamericana seja o resultado da deficiente educação do subcontinente, quando há uma série de variáveis determinantes de igual ou maior importância, como são: a dívida externa; a corrupção das elites; o protecionismo do primeiro mundo que se beneficia dez vezes mais do que lhe dá em termos de ajuda.

Sendo assim, a tentativa proposta não soluciona o problema, mas o transfere para outras esferas da sociedade. A solução deveria estar não somente na educação, como também na economia (políticas de assistência social, abertura de créditos para financiamento de empreendimentos e expansão do mercado de trabalho), na diminuição da fome e subnutrição, no combate à corrupção, no acesso a formas diferentes de lazer, esporte e cultura, dentre outros.

Portanto, podemos perceber que tal projeto não garante a almejada integração entre os diferentes grupos sociais e econômicos da sociedade, mas, no máximo, garante uma inclusão dos desfavorecidos à educação superior, o que, por sua vez, não significa a permanência e conclusão dos seus estudos.

Se quisermos realmente garantir a integração da parcela da população furtada de sua parte dos direitos constitucionais, é necessário encarar o problema de uma forma mais ampla, ou seja, uma discussão que não trate dos temas de forma fragmentada - que trate de maneira articulada os aspectos políticos, econômicos, sociais, científicos, culturais, enfim e que não envolva apenas o patronato das instituições privadas, sindicatos e o governo, mas que também envolva a sociedade civil interessada.

\section{A POLÍTICA NEOLIBERAL E A DEFENESTRAÇÃO DA EDUCAÇÃo BRASILEIRA}

No que tange à educação, há inúmeros pontos em que poderíamos nos deter, tais como, valorização do profissional da educação com aumento salarial e avaliação de seu desempenho; reivindicação por uma escola única com educação básica pública, gratuita, laica e de qualidade para todos; forma de acesso mais democrática à educação superior; ou ampliação de vagas nas instituições públicas federais de educação superior sem perda de qualidade, dentre inúmeros outros aspectos. 
Entretanto, os pontos acima citados já vem sendo discutidos na atualidade. Até mesmo observamos que, durante as greves na educação, alguns sindicatos de maneira corporativista, resumem suas lutas à exigência de melhores salários, sem evidenciar outros pontos também importantes para quem almeja uma sociedade menos desigual. Não estamos querendo dizer que a exigência por salários menos aviltantes seja tratada à revelia, mas que, além disso, também haja uma discussão em torno de outros aspectos muitas vezes omitidos.

Dessa forma, neste trabalho nos deteremos à forma mais utilizada de acesso ao ensino superior no país: o vestibular. Mostraremos que ela reflete-se negativamente na forma de atuação pedagógica empreendida dentro das salas de aula das escolas públicas e particulares, submete a educação a uma lógica de mercado e provoca uma enorme discrepância de conhecimentos entre os estudantes, refletindo-se no preenchimento de vagas das instituições de ensino superior públicas brasileiras.

Iniciando um diagnóstico sobre a educação no Brasil, percebemos que, atualmente, o seu estado de enfermidade encontra-se bastante grave. A intensificação desse estado clínico aumentou com a propagação das idéias neoliberais durante a abertura econômica promovida pelo Brasil a partir dos anos 90. Boito Jr (2002) mostra que é a partir dessa década que há uma maior abertura econômica com aumento das privatizações, negociação de acordos comerciais, liberalização da economia, maiores investimentos estrangeiros em setores antes monopolizados pelo capital nacional, redução da participação do Estado em políticas intervencionistas e de promoção do bem-estar social.

Essas medidas acabaram por criar um exército de reserva de trabalhadores, ou seja, o surgimento de um certo número de desempregados que tinha como um dos objetivos enfraquecer as lutas dos sindicatos. A partir de então, o conjunto dos trabalhadores no Brasil e, em especial, os trabalhadores da educação, têm vivido uma situação bastante difícil de desvalorização da média salarial e desprestígio da função de educador. De acordo com Boito Jr (2002, Disponível em: <http://www.espacoacademico.com.br/014/14cboito.htm>. Acesso em 18 dez. 2004.),

a substituição do desenvolvimentismo pelo modelo capitalista neoliberal, aliada às dificuldades crescentes do movimento operário e popular na década de 1990, levou ao declínio da escola pública, à privatização do ensino, à conversão da educação em mercadoria e à mudança no perfil da universidade.

A partir dessa nova realidade, o capital privado ganhou estímulo para se proliferar em todos os setores da sociedade. A educação também não deixou de ser afetada. Desde então, o número de instituições privadas de ensino aumentou vertiginosamente. A sede pelo lucro e a ganância pelo dinheiro transformou essas instituições de ensino em empresas super lucrativas e os estudantes em mercado a serem conquistados.

Essa expansão da rede de ensino privada além de acentuar o apartheid social, também tornou quase única a prática pedagógica baseada na concepção bancária da educação. Segundo Freire (1987, p. 57), na educação bancária “o educador aparece como seu indiscutível agente, como o seu real sujeito, cuja tarefa indeclinável é 'encher' os educandos dos conteúdos de sua narração”. O educando seria, então, uma espécie de vasilha ou depósito, no qual o educador teria a função de enchê-lo com palavras desvinculadas de suas ações práticas e da sua vida quotidiana. 
É a partir da valorização desse modelo pedagógico que o professor também deixará de cumprir a sua função de educador, pois privilegia-se o professor como vomitador de conteúdos e o aluno como puro receptor. Nesse caso, o olhar crítico, inquieto e curioso do educando é freado, anulado e sufocado por aquele que ensina, impossibilitando o desenvolvimento do pensamento e contribuindo para a timidez e inautenticidade do educando.

Mesmo aqueles (poucos, muitos?) professores, que contagiados pela possibilidade de participar positivamente da transformação da vida dos educandos e da sociedade, muitas vezes não podem ir muito além, pois a estrutura educacional do país os torna reféns das escolas privadas e facilita a prática da educação bancária.

Isso ocorre porque o que mais interessa a essas escolas participantes dessa lógica capitalista é o deslocamento dos estudantes para as universidades. E até agora, nesse sentido, o ensino tipicamente bancário vem dando resultados. Sendo assim, o conteúdo escolar é padronizado com base no vestibular, como também toda a equipe formada (professores, psicólogos e pedagogos) é construída tendo em vista a aprovação para a universidade. Formam-se verdadeiras equipes especializadas para o vestibular, que vendem "fórmulas" e ilusões, fazendo pais e alunos acreditarem que somente elas têm a solução para a aprovação do estudante na universidade.

Portanto, os conteúdos, a equipe pedagógica e o vestibular formam o tripé da máquina de tortura que, além de manter o conhecimento decapitado, atormenta e prende "à força” os alunos em sala de aula. Os educandos são obrigados a assistir cada uma das disciplinas seguindo o binômio fordista-taylorista de produção. Toca a "sirene", absorvese a matemática. Toca novamente, esquece-se o que foi absorvido e passa-se a absorver a geografia e assim por diante. Não há uma ligação entre as disciplinas lecionadas dentro da sala de aula, assim como, não há vínculo entre elas e a vida social dos alunos.

Percebe-se, portanto, que o grande marketing dessas escolas não é a educação na vida e para a vida, mas a educação para o vestibular e os dados estatísticos fornecidos pelas universidades são fontes de alimentação dessa lógica nefasta de mercado na educação. Atraídos pelo falso discurso e pelos resultados "positivos", a sociedade e os próprios pais dos educandos também passam a acreditar que o melhor para os seus filhos é a educação visando o vestibular. Para Rubem Alves (2004, p. 11), “os pais são os maiores inimigos da educação, porque eles não estão interessados na educação dos filhos; estão interessados em que eles estejam preparados para passar no vestibular”.

Tal lógica é perversa, pois transforma o professor em um mero "atravessador de conteúdos”, possibilitando a desvalorização da profissão, já que qualquer um pode entrar em uma sala de aula e fazer o mesmo por alguns minutos. Entretanto, o mais grave é quando a mesma lógica difundida entre as escolas de ensino privado é transferida para a rede de ensino público. O professor aliena-se de seu verdadeiro papel, contribui para a permanência do status quo social e torna sua profissão desprestigiada e desvalorizada.

Com base nisso, o que nos parece é que a educação no Brasil está andando à contramão das novas idéias que surgem pelo mundo. Enquanto pensadores como Boaventura dos Santos (1997; 2002), Edgar Morin (2001), Fritjof Capra (1982), Leonardo Boff (1999) e Ubiratan D’Ambrósio (1998), dentre outros, questionam a fragmentação das ciências e do conhecimento e propõe uma nova sociedade com bases interdisciplinares e 
holísticas vemos, a cada dia, surgir no país cursinhos especializados. Pior que isso! Vê-se que a sociedade naturaliza essa difusão indiscriminada de cursinhos especializados. Basta observar que nas últimas propagandas eleitorais vêm aparecendo propostas como: criação de cursinhos para a população mais carente. Tal proposta é vergonhosa, pois não questiona as raízes do problema educacional do nosso país e propõe um mecanismo que, por si só, já traz danos muitos sérios à educação nacional. Isso se constitui em uma tentativa de oferecer esmolas em troca de votos à população mais carente.

\section{O REENCONTRO COM A ESPERANÇA: PROPOSTAS PARA A DIFÍCIL E LONGA JORNADA}

Enfim, diante do grave quadro exposto até o momento, para revertê-lo propomos, em seguida, algumas políticas que devem ser amplamente discutidas com os vários segmentos da sociedade.

Primeiro, implementação de uma escola única, com educação básica, gratuita, laica, de qualidade e de acesso universal. Só a partir dessa alternativa poder-se-ia democratizar o acesso às universidades públicas brasileiras. O nível de educação que separa as escolas de ensino privado das redes de ensino público é tão grande que uma pífia parte da população mais carente é aprovada no vestibular. E mesmo assim nos cursos menos valorizados sócio-economicamente. Uma das soluções estaria, portanto, na equalização do nível de conhecimento.

Segundo, a necessidade de se discutir sobre a elaboração dos conteúdos programáticos. Para Paulo Freire (1992, p. 110), isso significa "saber quem escolhe os conteúdos, a favor de quem e de que estará o seu ensino, contra quem, a favor de que, contra que". Para isso, a participação da sociedade é muito importante. Seja ele um cozinheiro, pedreiro, marceneiro, médico, ambulante, advogado, enfim. Especialistas educacionais, comunidade local, associações, enfim, todos devem estar envolvidos na prática educativa da escola e, por isso, devem participar da organização programática dos conteúdos disciplinares. Dessa forma, daremos um passo para rompermos com uma tradição discriminatória, elitista e autoritária de sociedade que acredita que o ser humano "inculto" não é capaz de fazer sua própria leitura do mundo e contribuir para a construção dos saberes necessários à formação do cidadão.

Um terceiro aspecto muito importante está na pedagogia utilizada dentro da sala de aula. Para que o ambiente escolar deixe de ser uma grande máquina de tortura faz-se necessária a educação para a vida e na vida. Os conhecimentos devem estar interligados e conectados com o cotidiano dos educandos. "Nossa civilização e, por conseguinte, nosso ensino privilegiou a separação em detrimento da ligação (MORIN, 2001, p. 24)”. Uma reforma na educação do Brasil, portanto, deveria incluir mudanças na prática pedagógica do professor visando uma educação emancipadora. Isso significa que a formação do educador deve ser rediscutida com o objetivo de esse profissional revisitar a sua trajetória histórico-ideológica dentro da sociedade, compreender o sentindo humanizador de sua função, assim como, ser capaz de acompanhar as transformações tecnológicas e pedagógicas do mundo contemporâneo.

A remuneração dos educadores seria um quarto aspecto a ser bastante discutido e que contribui para a qualidade da educação. Para Capistrano (2003, p. 02), "talvez as 
razões da falência da profissão de professor estejam realmente na diminuição do poder aquisitivo, posto que, numa sociedade na qual o caráter de uma pessoa é proporcional ao limite do seu cartão de crédito, não ter dinheiro parece ainda ser o pior dos pecados morais”. Valorização com concessão de direitos, esse também deve ser um dos pontos pretendidos na reforma da educação em todos os seus níveis, pois o cuidado com a educação exige o extremo cuidado não apenas com o educando, como também, com o educador. Nesse sentido lembramos Freire (1996, p. 66). Para ele,

a luta em favor do respeito aos educadores e à educação inclui que a briga por salários menos imorais é um dever irrecusável e não só um direito deles. A luta dos professores em defesa de seus direitos e de sua dignidade deve ser entendida como um momento importante de sua prática docente, enquanto prática ética.

Por último, propomos uma medida que, em primeira análise parece ser absurdo: a extinção de qualquer mecanismo de acesso às universidades. As formas de acesso, baseadas em provas avaliativas, não avaliam de maneira efetiva a capacidade de aprendizagem do aluno. Elas foram construídas para responder ao precário e atual sistema educacional vigente no nosso país. Como sugere MORETTO (2002), a prova não deve ser um acerto de contas, mas um momento privilegiado e prazeroso de estudo. Com a implementação de uma ampla reforma da educação, esses mecanismos de acesso deverão desaparecer e serem substituídos por outras formas de seleção. Ao invés da seleção ser realizada antes da entrada do estudante ao ensino superior, ela realizar-se-ia durante a sua vida acadêmica dentro do curso escolhido, por exemplo.

No entanto, a educação sozinha não muda a sociedade, mas constitui-se em um dos elementos que nos ajudarão a construir um novo modelo de desenvolvimento sócioeconômico para o país, pois o atual modelo não é compatível com as idéias propostas, já que ele vem aprofundando a nossa dependência econômica e tecnológica, que prioriza as exportações geradas pelo agronegócio, submete o país aos ditames econômicos dos órgãos financeiros internacionais, aplica a política de juros altos que privilegia os bancos e os agiotas estrangeiros, assim como, produz um enorme superávit primário destinado ao pagamento da dívida externa.

Um modelo próprio de desenvolvimento sócio-econômico significa uma efetiva política de Reforma Agrária, investimentos na área de saúde com maior oferta de assistência médico-hospitalar, maior participação da população na política do país através dos referendos e plebiscitos, investimento em áreas produtivas com o apoio às pequenas e micro empresas nacionais para a geração de emprego, o surgimento de uma relação harmoniosa e de comunhão entre o ser humano e a natureza, renegociação ou fim do pagamento da dívida externa, dentre outros aspectos.

Assim, sem essa recusa ao receituário neoliberal, qualquer reforma educacional empreendida pelo governo dificilmente promoverá significativas melhorias nos índices sociais do país, pois, como já foi dito anteriormente, a educação sozinha não mudará o Brasil.

\section{CONSIDERAÇÕES FINAIS}

Finalizando, ao elaborar o presente artigo tivemos como preocupação realizar uma síntese de idéias, pensamentos e propostas de vários autores, assim como, inserir nossas 
análises em torno dos danos que o vestibular acarreta à educação nacional. Constatamos que as dificuldades não são pequenas, pelo contrário, são enormes e estamos conscientes de que as informações contidas neste artigo não bastam, mas são preciosas para provocar uma discussão mais ampla e ajudar àqueles que estão interessados em aprofundar mais os estudos sobre esse tema tão provocador e tão caro à educação e à sociedade.

\section{REFERÊNCIAS}

ALVES, R. Revista Profissão Mestre. Ano 6 - No 62 - Novembro, 2004.

BOFF, L. Saber Cuidar: Ética do Humano-Compaixão pela Terra. $11^{\text {a }}$ ed. São Paulo: Vozes, 1999.

BOITO JR. A. Neoliberalismo, sistema educacional e trabalhadores em educação no Brasil. Disponível em: <http://www.espacoacademico.com.br/014/14cboito.htm>. Acesso em 18 dez. 2004.

D'AMBROSIO, U. Conhecimento e consciência: o despertar de uma nova era. In: Conhecimento, cidadania e ambiente. São Paulo: Fundação Peirópoli, 1998, p.11-46

KUENZER, A. Z.; CALAZANS, M. J. C.; GARCIA, W. Planejamento e educação no Brasil. $3^{\text {a }}$ ed. São Paulo: Cortez, 1996. (Coleção Questões da Nossa Época; v. 21).

CAPISTRANO, P. O Fantasma na sala de aula. Jornal Tribuna do Norte. Natal - RN, terça-feira, 23 de setembro de 2003

CAPRA, F. O Ponto de Mutação. São Paulo: Cultrix, 1982.

FREIRE, P. Pedagogia do oprimido. In: A concepção bancária da educação como instrumento da educação. Seus pressupostos. 28ª ed. Rio de Janeiro, Paz e Terra, 1987.

Pedagogia da Esperança: Um reencontro com a pedagogia do oprimido. $7^{\mathrm{a}}$ ed. São Paulo: Paz e Terra, 1992.

Pedagogia da Autonomia: saberes necessários à prática educativa. $30^{\mathrm{a}}$ ed. São Paulo: Paz e Terra, 1996.

Ministério da Educação e Cultura. Reforma da Educação Superior. Disponível em: <www.mec.gov.br/reforma>. Acesso em 31 dez 2004.

MORETTO, V. P. Prova - um momento privilegiado de estudo - não um acerto de contas. $2^{\text {a }}$ ed. Rio de Janeiro: DP\&A, 2002.

MORIN, E. A cabeça bem-feita: repensar a reforma, reformar o pensamento. $3^{\mathrm{a}}$ ed. Rio de Janeiro: Bertrand Brasil, 2001.

MOURA, D. Sociedade, educação tecnologia e os usos das TIC nos processos educativos. In: Trabalho necessário. Revista Eletrônica do neddate. Disponível em: $<$ http://www.uff.br/trabalhonecessário/> Acesso em 15 ago. 2004.

SANTOS, B. Pela mão de Alice: o social, o político na pós-modernidade. São Paulo: Cortez, 1997. 
Um discurso sobre as ciências. Porto: Afrontamento, 2002.

SAVIANI, D. As teorias da educação e o problema da marginalidade. In: Escola e Democracia. 33 ${ }^{\mathrm{a}}$ ed. Campinas: Autores associados, 2000. 